\title{
Analisis Kebutuhan Mahasiswa terhadap Pengembangan E-Modul Fisika Matematika I di Program Studi Pendidikan Fisika FKIP Universitas Jambi
}

\author{
Mashelin Wulandari ${ }^{1)^{*},}$, Astalini Astalini ${ }^{1)}$, Darmaji Darmaji ${ }^{1)}$ \\ ${ }^{1)}$ Pendidikan Fisika Fakultas Keguruan dan Ilmu Pendidikan, Universitas Jambi \\ *mashelinwulandari@gmail.com
}

\begin{abstract}
Abstrak: Penelitian ini bertujuan untuk mengemukakan hasil analisis kebutuhan mahasiswa terhadap bahan ajar Fisika Matematika I, dimana bahan ajar ini berupa e-modul.Penelitian ini mengambil subjek mahasiswa kelas reguler A angkatan 2019 Program Studi Pendidikan Fisika FKIP Universitas Jambi yang berjumlah sebanyak 35 orang mahasiswa. Penelitian yang dilakukan merupakan penelitian dengan metode campuran (mixed method). Penelitian dengan metode campuran ialah menggabungkan penelitian kuantitatif dan kualitatif. Data pada penelitian kuantitatif diperoleh dari angket kebutuhan mahasiswa, dan data kualitatif diperoleh dari hasil wawancara pada mahasiswa. Data kuantitatif dianalisis menggunakan statistik deskriptif dengan bantuan aplikasi SPSS v.25 dimana hasil yang diperoleh adalah 62,9\% menyatakan bahwa e-modul Fisika Matematika I ini dibutuhkan. Sedangkan data kualitatif dianalisis menggunakan Miles \& Huberman dimana hasil wawancara ini menunjukkan bahwa mahasiswa membutuhkan bahan ajar tambahan pada perkuliahan Fisika Matematika I yang menggunakan bahasa Indonesia dan yang lebih menarik agar mahasiswa mampu memahami materi dengan mudah dan terperinci. Dengan adanya e-modul ini, mahasiswa diharapkan dapat belajar secara mandiri atau tanpa bimbingan langsung dari dosen.
\end{abstract}

Kata Kunci: Analisis Kebutuhan, E-Modul, Fisika Matematika I, Pendidikan Fisika.

\section{Pendahuluan}

Kemajuan teknologi informasi pada era revolusi 4.0 menjadi salah satu industri dengan pertumbuhan yang paling pesat pada saat ini. Hal ini memberikan kemudahan dalam banyak hal, seperti memperoleh informasi (Marisda \& Handayani, 2020). Perkembangan teknologi tidak dapat dipungkiri telah merambah begitu luas pada berbagai bidang kehidupan, salah satunya adalah bidang pendidikan. Salah satu perubahan dalam dunia pendidikan sebagai perkembangan teknologi di era 4.0 adalah dengan digitalisasi (Rini \& Cholifah, 2020). Hal ini ditandai dengan munculnya berbagai kegiatan berbasis teknologi dan internet, seperti e-government, e-medicine, e-laboratory, serta e-education dimana semuanya berbasis elektronik (Diani \& Hartati, 2018).

Pendidikan memiliki peran yang sangat penting dalam diri seseorang. Salah satu tujuan pendidikan adalah mendidik individu agar dapat menyesuaikan dan menempatkan diri dengan layak di lingkungannya (Astalini et al., 2018). Dengan adanya pendidikan diharapkan peserta didik mampu mempersiapkan dirinya menjadi orang yang memberikan kontribusi positif bagi masyarakat nantinya (Kurniawan et al, 2019). Artinya, pendidikan berupaya untuk menghasilkan SDM yang berkualitas, baik dimasa kini hingga masa mendatang. Sejak dilakukan pembelajaran online, berbagai upaya terus dilakukan oleh sekolah untuk memenuhi kebutuhan peserta didik. Tetapi nyatanya guru masih sering menjadi sumber tunggal dalam belajar, sehingga siswa terbiasa pasif dan mengakibatkan motivasi belajar siswa menjadi rendah (Cholik, 2017).

Salah satu mata kuliah wajib bagi mahasiswa pendidikan fisika adalah fisika matematika. Fisika matematika merupakan mata kuliah yang mengabungkan pelajaran fisika dengan matematika (Wilujeng \& Permatasari, 2019). Mata kuliah Fisika Matematika di program studi Pendidikan Fisika FKIP Universitas Jambi dibagi menjadi tiga bagian mata kuliah, yaitu Fisika Matematika I, II dan III dengan masing-masingnya berjumlah 3 sks. Salah satu pokok bahasan berdasarkan Rencana Pembelajaran Semeser (RPS) pada mata kuliah Fisika Matematika I adalah turunan fungsi implisit dari materi diferensial parsial. Persamaan diferensial 
merupakan persamaan turunan yang memuat dua atau lebih variabel bebas, sama halnya dengan turunan implisit yang memuat lebih dari dua variabel yangmana ketika satu variabel diturunkan maka variabel lain tidak dapat dianggap konstan. Pada materi ini bahasan yang dibahas adalah turunan fungsi implisit, aplikasi diferensial parsial pada persoalan maksimum dan minimum, persoalan minimum dan maksimum dengan kendala (Lagrange Multipliers), dan permasalahan titik batas. Sehingga mahasiswa menganggap mata kuliah ini sulit (Nurhidayah et al., 2018). Hal ini mengakibatkan penguasaan materi menjadi tidak merata dan hasil belajar sebagian mahasiswa rendah (Marisda \& Handayani, 2020). Sehingga dibutuhkan sumber belajar tambahan untuk mendukung kegiatan belajar dan mengajar yang dapat memudahkan proses pembelajaran.

Buku yang saat ini digunakan pada mata kuliah Fisika Matematika I ini adalah buku karya dari Mary L. Boas dengan judul Mathematical Methods in the Physical Sciences sebagai buku utama dan menggunakan bahasa inggris secara keseluruhan (Ellianawati \& Wahyuni, 2012). Kondisi ini menjadi salah satu penyebab kurangnya kemampuan siswa dalam memahami materi yang disajikan pada mata kuliah ini. Dengan demikian, salah satu solusi yang dapat digunakan untuk mendukung perkuliahan dan pemahaman materi oleh mahasiswa adalah menggunakan modul pembelajaran dalam bentuk elektronik.

Modul elektronik dikenal juga dengan e-modul. E-modul ini digunakan agar siswa lebih tertarik untuk belajar. Karena Penyampaian materi secara langsung (konvensional) yang dilakukan tanpa pengulangan membuat siswa kurang memahami materi (Rozy \& Anggana, 2016). Penggunaan modul dengan model cetak tidak mutlak tidak layak untuk dipilih, tetapi dari beberapa sisi modul elektronik lebih unggul karena tidak mudah rusak dan sobek serta tidak membosankan. Selain itu e-modul ini adalah dapat digunakan dimana saja dan kapan saja tanpa keterbatasan tempat dan waktu. Hal inilah yang menjadi latar belakang perlunya dilakukan penelitian ini. Selain itu, alasan peneliti melakukan penelitian ini adalah belum ditemukan penelitian yang sama dengan penelitian yang dilakukan oleh peneliti

\section{Metode}

Penelitian yang dilakukan merupakan metode campuran atau mixed method. Mixed method atau metode campuran adalah penelitian yang menggabungkan penelitian kualitatif dengan penelitian kuantitatif (Ningsih \& Arief, 2021). Penelitian ini dilakukan di Universitas Jambi, tepatnya pada program studi pendidikan fisika fakultas keguruan dan ilmu pendidikan. Populasi dalam penelitian ini adalah mahasiswa pendidikan fisika angkatan tahun 2019. Sedangkan sampel pada penelitian ini adalah kelas reguler A program studi Pendidikan Fisika FKIP Universitas Jambi yang berjumlah sebanyak 35 orang mahasiswa.

Teknik pengumpulan data yang dilakukan adalah dengan menggunakan angket/kuisioner dan wawancara. Teknik pengumpulan data ini terdiri dari pengumpulan data kuantitatif dan kualitatif. Data kuantitatif diperoleh dengan cara menyebarkan angket kebutuhan kepada mahasiswa. Instrumen angket yang digunakan terdiri dari 6 pernyataan yang menggunakan skala Likert dengan 5 pilihan jawaban, yaitu sangat tidak setuju, tidak setuju, netral, setuju, dan sangat setuju. Adapun skala Likert adalah suatu skala penilaian yang terdiri dari beberapa pilihan skala dengan nilai pada setiap skala untuk mengukur tingkat persetujuan terhadap sesuatu yang menjadi objek penelitian (Maryuliana et al., 2016). Sedangkan data kualitatif didapatkan dari hasil wawancara kepada mahasiswa mengenai kebutuhan terhadap e-modul fisika matematika I. Adapun wawancara sendiri ialah metode yang penting dalam melakukan penelititan untuk kelengkapan dalam mengumpulkan data yang dibutuhkan (Sakti \& Hikayati, 2017). Setelah data dikumpulkan, maka selanjutnya data dianalisis. Analisis data kuantitatif dilakukan dengan mengunakan deskriptif statistik, sedangkan analisis data kualitatif mengacu pada Miles and Huberman.

Tabel 1. Rentang dan kriteria skor angket kebutuhan mahasiswa

\begin{tabular}{cc}
\hline Rentang Skor & Kriteria \\
\hline $6,0-10,8$ & Sangat Dibutuhkan \\
$10,9-15,6$ & Dibutuhkan \\
$15,7-20,4$ & Cukup Dibutuhkan \\
$20,5-25,2$ & Dibutuhkan \\
$25,3-30,0$ & Sangat Dibutuhkan \\
\hline
\end{tabular}


Angket kebutuhan mahasiswa dianalisis dengan menggunakan rentang skor dan kriteria untuk menentukan kesimpulan akhir dari hasil yang diperoleh. Sedangkan wawancara dilakukan dengan menggunakan instrumen pedoman wawancara. Adapun rentang dan kriteria skor angket kebutuhan dapat dilihat pada tabel 1 dan kisi-kisi pedoman wawancara dapat dilihat pada tabel 2.

Tabel 2. Kisi-kisi pedoman wawancara mahasiswa terhadap mata kuliah Fisika Matematika I

\begin{tabular}{clc}
\hline No & \multicolumn{1}{c}{ Indikator } & No. Butir \\
\hline 1 & Mengikuti proses perkuliahan Fisika Matematika I & $1,2,3$ \\
2 & Bahan ajar yang digunakan pada perkuliahan & 4,5 \\
3 & Kendala atau masalah pada perkuliahan & 6,7 \\
4 & Solusi yang diharapkan oleh peserta perkuliahan & 8 \\
5 & Jika dibuatkan modul, modul seperti apa yang diharapkan oleh peserta perkuliahan & $9,10,11,12$ \\
\hline
\end{tabular}

\section{Hasil dan Pembahasan}

Penelitian ini dilakukan pada program studi Pendidikan Fisika kelas reguler A FKIP Universitas Jambi. Teknik pengumpulan data yang dilakukan dalam penelitian ini adalah dengan mengumpulkan data kuantitatif dan kualitatif. Data kuantitatif diperoleh dari hasil penyebaran angket kebutuhan mahasiswa, sedangkan data kualitatif diperoleh dari hasil wawancara. Setelah data terkumpul, kemudian data dianalisis menggunakan masing-masing jenis analisis data. Data kuantitatif yang diperoleh dalam penelitian dianalisis secara statsitik deskriptif berdasarkan skor yang diperoleh dari angket. Angket ini menggunakan skala likert dengan 5 pilihan jawaban. Adapun data hasil deskriptif yang diperoleh dapat dilihat pada tabel 3 berikut.

Tabel 3. Hasil statistik deskriptif angket kebutuhan mahasiswa terhadap e-modul fisika matematika I

\begin{tabular}{cccccc}
\hline Rentang Skor & F & $\%$ & Mean & Minimum & Maksimum \\
\hline $6,0-10,8$ & 0 & 0 & & & \\
$10,9-15,6$ & 2 & 5,7 & & & \\
$15,7-20,4$ & 3 & 8,6 & 22,7 & 12,0 & 28 \\
$20,5-25,2$ & 22 & 62,9 & & & \\
$25,3-30,0$ & 8 & 22,9 & & & \\
\hline
\end{tabular}

Tabel 3 menunjukkan hasil statistik deskriptif untuk angket kebutuhan mahasiswa terhadap e-modul Fisika Matematika I. Berdasarkan tabel tersebut dapat dilihat bahwa tidak ada yang menyatakan bahwa e-modul ini sangat tidak dibutuhkan, 2 orang menyatakan bahwa e-modul ini tidak dibutuhkan, 3 orang menyatakan bahwa e-modul ini cukup dibutuhkan, 22 orang menyatakan bahwa e-modul ini dibutuhkan, dan 8 orang menyatakan bahwa e-modul ini sangat dibutuhkan. Jika disajikan dalam bentuk persentase, maka dapat diketahui bahwa 0\% mahasiswa menyatakan bahwa e-modul ini sangat tidak dibutuhkan, 5,7\% mahasiswa menyatakan bahwa e-modul ini tidak dibutuhkan, 8,6\% mahasiswa menyatakan bahwa e-modul ini cukup dibutuhkan, 62,9\% mahasiswa menyatakan bahwa e-modul ini dibutuhkan, dan 22,9\% mahasiswa menyatakan bahwa e-modul ini sangat dibutuhkan. Namun hasil yang lebih dominan menyatakan bahwa e-modul ini dibutuhkan dengan persentase sebesar $62,9 \%$. Selain itu, dapat dilihat bahwa mean atau nilai rata-ratanya adalah 22,7, dengan nilai minimum sebesar 12, dan nilai maksimum sebesar 28.

Berdasarkan hasil statistik angket kebutuhan mahasiswa yang diperoleh, dapat diketahui bahwa sebagian besar mahasiswa menyatakan setuju dengan adanya pengembangan bahan ajar Fisika Matematika I agar lebih mudah untuk dipahami. Karena penggunaan bahan ajar yang menggunakan bahasa Inggris dianggap sulit bagi mahasiswa. Hal ini didukung oleh penelitian yang dilakukan oleh Pawestri et al (2013), bahwa kurangnya penguasaan bahasa Inggris bagi guru maupun siswa sebagai bahasa pengantar dalam pembelajaran dapat membuat siswa mempunyai beban ganda yaitu penguasaan bahasa Inggris sebagai bahasa pengantar dalam pembelajaran dan pencapaian kompetensi dasar, hingga pencapaian hasil belajar yang masih diragukan. Sedangkan pembelajaran Fisika Matematika membutuhkan penguasan mahasiswa baik secara konsep maupun secara matematis. Karena salah satu tujuan dari mata kuliah ini agar mahasiswa mampu merumuskan proses fisika kedalam pernyataan yang matematis (Dayati, 2021). Sehingga mata kuliah ini dirancang untuk mempersiapkan mahasiswa dalam menguasai teknik analisis matematis dari suatu konsep fisika (Ellianawati \& Wahyuni, 2012). 
Setelah data kuantitatif terkumpul, selanjutnya peneliti juga mengumpulkan data kualitatif yang diperoleh dari hasil wawancara. Hasil wawancara digunakan untuk mendukung hasil data kuantitatif yang didapatkan. Adapun hasil wawancara yang diperoleh adalah mahasiswa menyatakan bahwa pengembangan $e$ modul pada mata kuliah Fisika Matematika I ini dibutuhkan. Hal ini dapat dilihat pada hasil wawancara yang telah dilakukan berikut ini:

Apakah saudara sudah mengikuti perkuliahan Fisika Matematika I?

Jawaban: Iya, sudah.

Apakah ini pertama kali saudara mengikuti perkuliahan Fisika Matematika I?

Jawaban: Iya.

Berapa kali saudara mengikuti perkuliahan Fisika Matematika I?

Jawaban: 1 kali (satu semester).

Apakah saudara memiliki literasi pada perkuliahan Fisika Matematika I?

Jawaban: Iya, saya punya.

Bagaimana menurut saudara tentang literasi yang digunakan pada perkuliaham Fisika Matematika I?

Jawaban: Sulit untuk dipahami, karena terkendala dalam mentranslate ke dalam bahasa Indonesia.

Apakah saudara memiliki kendala atau masalah selama perkuliahan Fisika Matematika I?

Jawaban: Iya, terdapat beberapa kendala.

Apakah salah satu kendala atau masalah selama perkuliahan Fisika Matematika I terletak pada bahan ajar?

Jawaban: Iya.

Apa yang saudara harapkan dari bahan ajar Fisika Matematika I?

Jawaban: Semoga terdapat buku yang berbahasa Indonesia dan dikembangkan dengan inovasi-inovasi yang dapat dipahami oleh mahasiswa.

Apakah saudara senang jika Fisika Matematika I ada dalam bentuk modul elektronik?

Jawaban: Iya, senang sekali.

Bagaimana menurut saudara jika Fisika Matematika I dibuatkan modul perkuliahan berbasis elektronik?

Jawaban: Sangat setuju, karena dapat mempermudah mahasiswa dalam mempelajari materi.

Jika ada modul elektronik Fisika Matematika I, apa menurut saudara dapat membantu proses perkuliahan Fisika Matematika I?

Jawaban: Iya, sangat membantu.

Jika ada modul elektronik Fisika Matematika I, apa yang saudara harapkan dari modul elektronik tersebut?

Jawaban: Semoga modul elektronik yang dihasilkan menggunakan bahasa Indonesia yang dapat membantu memahami materi dengan penjelasan yang detail dan terperinci.

Berdasarkan hasil analisis hasil wawancara terhadap mahasiswa, maka dapat disimpulkan bahwa mahasiswa membutuhkan bahan ajar tambahan dalam perkuliahan Fisika Matematika I, khususnya yang menggunakan bahasa Indonesia. Namun, pemilihan bahan ajar tidak bisa asal dipilih, melainkan melalui pertimbang. Salah satu hal yang menjadi pertimbangan dalam pemilihan bahan ajar adalah bahan ajar yang baik dan juga menarik (Rizki \& Linuhung, 2016). Bahan ajar yang baik dapat digunakan untuk membantu siswa dalam mencapai kompetensi yang diharapkan (Nisa \& Supriyanto, 2016). Sedangkan bahan ajar yang menarik diperlukan agar siswa tertarik untuk mempelajari materi, baik dari segi tampilan maupun konten yang sesuai dengan kebutuhan siswa terhadap materi yang dipelajari (Rizki \& Linuhung, 2016). Sehingga salah satu solusi yang dapat ditawarkan adalah menggunakan modul elektronik atau e-modul. 
E-modul atau modul elektronik lahir sebagai inovasi pengembangan modul cetak ke bentuk modul digital (Sugihartini \& Jayanta, 2017). E-modul ini disusun secara terstruktur menjadi unit pembelajaran terkecil guna mencapai tujuan pembelajaran tertentu (Arsal et al., 2019). Tujuan e-modul ini agar siswa dapat belajar tanpa bimbingan guru atau dapat belajar secara mandiri (Sofyan et al., 2019). Hal ini dikarenakan kemandirian siswa diutamakan dalam menggunakan E-Modul (Rahayu, 2020: 399). Sehingga e-modul yang digunakan lebih efektif daripada buku cetak (Astalini, Darmaji, Kurniawan, Anwar, et al., 2019). Berdasarkan hasil data kuantitatif dan data kualitatif tersebut, maka dapat disimpulkan bahwa memang dibutuhkan pengembangan bahan ajar Fisika Matematika I berupa e-modul untuk mendukung dan memudahkan siswa dalam memahami materi pembelajaran.

\section{Simpulan}

Berdasarkan hasil penelitian yang telah diperoleh, maka dapat disimpulkan bahwa dibutuhkannya sumber belajar tambahan dalam bahasa Indonesia pada perkuliahan fisika matematika I. Karena penggunaan yang berbasis bahasa inggris memberikan kesulitan bagi mahasiswa dalam memahami materi yang dipelajari. Adapun solusi yang dapat dilakukan adalah dengan menggunakan modul elektronik atau e-modul. E-modul ini bertujuan agar siswa dapat belajar secara mandiri dengan kelebihan dapat digunakan kapan saja dan dimana saja. Kebutuhan mahasiswa terhadap e-modul ini dapat dilihat dari hasil angket kebutuhan mahasiswa yang menunjukkan hasil bahwa sebanyak 22 mahasiswa atau 62,9\% mahasiswa menyatakan bahwa e-modul ini dibutuhkan. Selain itu, hasil ini diperkuat dengan perolehan hasil wawancara yang menyatakan bahwa mahasiswa membutuhkan e-modul agar lebih mudah memahami materi dan pembelajaran menjadi lebih menarik.

\section{Ucapan Terima Kasih}

Peneliti mengucapkan terimakasih kepada pihak Universitas Jambi, khususnya kepada ketua program studi Pendidikan Fisika yang telah mengizinkan peneliti untuk melakukan penelitian. Selanjutnya tidak lupa peneliti mengucapkan terimakasih yang sebesar-besarnya kepada dosen pembimbing yang telah membimbing dan mengarahkan peneliti sehingga peneliti dapat menyelesaikan penelitian ini. Serta kepada rekan dan seluruh pihak yang telah membantu dalam penelitian ini.

\section{Daftar Pustaka}

Arsal, M., Danial, M., \& Hala, Y. (2019). Pengembangan Media Pembelajaran E-Modul Materi Sistem Peredaran Darah Pada Kelas XI MIPA SMAN 6 Barru The Development of E-Module Learning Media of Blood Circulatory System In Grade XI MIPA at SMAN 6 Barru. Jurnal Biologi Dan Pembelajarannya, 4(2), 434-442.

Astalini, A., Kurniawan, D. A., \& Putri, A. D. (2018). Identifikasi Sikap Implikasi Sosial dari IPA, Ketertarikan Menambah Waktu Belajar IPA, dan Ketertarikan Berkarir Dibidang IPA Siswa SMP Se-Kabupaten Muaro Jambi. Jurnal Tarbiyah: Jurnal Ilmiah Kependidikan, 7(2), 93-108. https://doi.org/10.18592/tarbiyah.v7i2.2142

Astalini, Darmaji, Kurniawan, W., Anwar, K., \& Kurniawan, D. A. (2019). Effectiveness of Using E-Module and E-Assessment. IJIM, 13(9), 21-39.

Cholik, C. A. (2017). Pemanfaatan Teknologi Informasi dan Komunikasi untuk Meningkatkan Pendidikan di Indonesia. Syntax Literate: Jurnal Ilmiah Indonesia, 2(6), 21-30.

Dayati, F. B. (2021). Kesulitan Belajar Mata Kuliah Matematika Fisika I Melalui Pembelajaran Daring Mahasiswa. Jurnal Pendidikan, Sains, Dan Humaniora, 9(6), 865-870.

Diani, R., \& Hartati, N. S. (2018). Flipbook berbasis literasi Islam: Pengembangan media pembelajaran fisika dengan 3D pageflip professional. Jurnal Inovasi Pendidikan IPA, 4(2), 234-244. https://doi.org/10.21831/jipi.v4i2.20819

Ellianawati, \& Wahyuni, S. (2012). Pengembangan Bahan Ajar Fisika Matematika Berbasis Self Regulated Learning Sebagai Upaya Peningkatan Kemampuan Belajar Mandiri. Jurnal Pendidikan Fisika Indonesia, 8(1), 
$33-40$.

Kurniawan, D. A., Astalini, A., Darmaji, D., \& Melsayanti, R. (2019). Students' attitude towards natural sciences. International Journal of Evaluation and Research in Education (IJERE), 8(3), 455-460. https://doi.org/10.11591/ijere.v8i3.16395

Marisda, D. H., \& Handayani, Y. (2020). Model Pembelajaran Kolaboratif Berbasis Tugas Sebagai Alternatif Pembelajaran Fisika Matematika. Fisika PPs UNM, 2(1), 9-12.

Maryuliana, Subroto, I. M. I., \& Haviana, S. F. C. (2016). Sistem Informasi Angket Pengukuran Skala Kebutuhan Materi Pembelajaran Tambahan Sebagai Pendukung Pengambilan Keputusan Di Sekolah Menengah Atas Menggunakan Skala Likert. Jurnal Transistor Elektro Dan Informatika, 1(2), 1-12.

Ningsih, I. Y., \& Arief, M. (2021). Bauran Promosi Pada Dealer Yamaha Tretan Motor Dengan Pendekatan Mixed Methods. Jurnal Kajian Ilmu Manajemen, 1(1), 1-8.

Nisa, H. U., \& Supriyanto, T. (2016). Pengembangan Bahan Ajar Membaca Sastra Legenda Bermuatan Kearifan Lokal Berbahasa Jawa. Seloka: Jurnal Pendidikan Bahasa Dan Sastra Indonesia, 5(2), 192-200.

Nurhidayah, Sairi, A. P., Hamdi, H., \& Alfitri, S. R. A. (2018). Peningkatan Motivasi Belajar Mahasiswa pada Mata Kuliah Fisika Metematika II Menggunakan Model Pembelajaran Kooperatif Tipe Jigsaw di Fakultas Sains dan Teknologi Universitas Jambi. Jurnal Ilmu Fisika Dan Pembelajarannya (JIFP), 2(1), 21-27.

Pawestri, U., Kurniawati, I., Prodi, M., Matematika, P., \& Prodi, D. (2013). Analisis Kesulitan Pembelajaran Matematika dengan Pengantar Bahasa Inggris pada Materi Pokok Bentuk Logaritma Kelas X IMERSI SMA Negeri Karangpandan Karanganyar 2012/2013. Jurnal Pendidikan Matematika Solusi, 1(1), 1-7.

Rahayu, I. (2020). The Development Of E-Modules Project Based Learning for Students of Computer and Basic Networks at Vocational School. Journal of Education Technology, 4(4), 398-403.

Rini, T. A., \& Cholifah, P. S. (2020). Electronic Module with Project Based Learning: Innovation of Digital Learning Product on 4.0 Era. Edcomtech: Jurnal Kajian Teknologi Pendidikan, 5(2), 155-161.

Rizki, S., \& Linuhung, N. (2016). Pengembangan Bahan Ajar Program Linear Berbasis Kontekstual dan ICT. Aksioma: Jurnal Pendidikan Matematika FKIP Univ. Muhammadiyah Metro, 5(2), 137-144.

Rozy, A. F., \& Anggana, Y. (2016). Pengembangan Media Pembelajaran Elektronika Berbasis 3D Pageflip pada Mata Pelajaran Penerapan Rangkaian Elektronika di SMK Negeri 1 Kediri. Jurnal Pendidikan Teknik Elektro Guru, 6(1), 1-7.

Sakti, H. G., \& Hikayati, S. (2017). Pengaruh Penggunaan Model Pembelajaran Air ( Auditory, Intellectualy, Repetition ) Terhadap Hasil Belajar Mata Pelajaran Matematika Pada Siswa Kelas VII SMP Negeri 2 Lembar Lombok Barat Tahun Pelajaran 2016 / 2017. Society, Jurnal Jurusan Pendidikan IPS Ekonomi, $\operatorname{VIII}(2), 68$.

Sofyan, H., Anggereini, E., \& Saadiah, J. (2019). Development of E-Modules Based on Local Wisdom in Central Learning. European Journal of Educational Research Volume, 8(4), 1137-1143. https://doi.org/10.12973/eu-jer.8.4.1137

Sugihartini, N., \& Jayanta, N. L. (2017). Pengembangan E-Modul Mata Kuliah Strategi Pembelajaran. Jurnal Pendidikan Teknologi Dan Kejuruan, 14(2), 221-230.

Sukendra, I. K. (2020). Pengaruh Model Pembelajaran SAVI terhadap Hasil Belajar Mahasiswa Pendidikan Matematika FMIPA dengan Mengontrol Disiplin Belajar. Widyari: Jurnal Pendidikan, 21(1). https://doi.org/10.5281/zenodo.3742507

Wilujeng, I., \& Permatasari, I. (2019). Pengembangan Buku Ajar Fisika Matematika Berbasis Kajian Kritis Materi Fisika Sekolah dan Integrasi Nilai- Nilai Karakter. Jurnal Inovasi Pendidikan Fisika Dan Integrasinya, 2(2), 1-12. 